\title{
Assessing delivery of mechanical ventilation: risks and benefits of large databases
}

\author{
May Hua ${ }^{1,2}$, Hayley B. Gershengorn ${ }^{3,4}$ and Hannah Wunsch ${ }^{1,5,6^{*}}$
}

(c) 2020 Springer-Verlag GmbH Germany, part of Springer Nature

Invasive mechanical ventilation is a key component of critical care medicine. Resource-intensive and expensive, it is an essential intervention to support many patients through critical illness. Examining and estimating system-wide capacity for mechanical ventilation, whether the system in question is a country, a region, or a group of hospitals, is often accomplished using population-level data. These data may be used to assess whether capabilities match current or projected needs, and may be used to evaluate differences in use and outcomes across a system or systems [1-3].

\section{Specific uses for population-level data}

Population-level data are often used to better understand the epidemiology and outcomes of mechanical ventilation. Such data have demonstrated that patients requiring mechanical ventilation span a wide age range, are highly comorbid, and account for an outsize percentage of overall hospital costs [4]. Studies across hospitals have shown substantial variation in use of mechanical ventilation and demonstrated the possibility of a volume-outcome relationship, with lower mortality at hospitals with higher rates of use $[5,6]$. Population-level data have also been used to understand temporal trends in use of mechanical ventilation. Over time, use of mechanical ventilation has increased and the treated population has changed, with patients having a higher severity of illness $[1,7]$. Furthermore, in the United States, the use of tracheostomy also increased (until 2008), with a concomitant increase in the use of post-acute care facilities [7, 8]. Recognition of these trends was important, as they informed the need to move beyond in-hospital endpoints to follow patients

\footnotetext{
*Correspondence: hannah.wunsch@sunnybrook.ca

${ }^{1}$ Department of Anesthesiology, Columbia University, New York, NY, USA

Full author information is available at the end of the article
}

post discharge to fully understand mechanical ventilation outcomes. Moreover, tracking of these trends can facilitate planning of post-acute care services to meet heightened demand.

Population-level data may be particularly useful for examining long-term outcomes requiring longitudinal follow-up. Studies using population-level data have documented an increased risk of long-term mortality, a transient increase in risk of psychiatric diagnoses and psychoactive medication prescriptions, and an increased need for subsequent healthcare utilization after episodes of prolonged mechanical ventilation [9-11]. Furthermore, outcome-focused studies have been used to identify patient populations where use of mechanical ventilation may be of limited benefit. A national study from Taiwan of patients with cancer who underwent prolonged mechanical ventilation demonstrated that 1 -year mortality was $85.7 \%$, and that patients with liver, lung or metastatic cancer had the worst survival [12]. In the United States, a study of nursing home residents with advanced dementia showed that use of mechanical ventilation increased over time in this population without an associated improvement in survival [13]; moreover, this trend of increasing use for patients with dementia was confirmed in a separate study using Canadian data, suggesting that such practices were not isolated to the US [2]. These studies, and others like them, have served to better inform the risk-benefit ratio for mechanical ventilation by clarifying what the long-term risks are, as well as what the benefit (in terms of survival) is likely to be.

\section{Considerations when using large databases to study mechanical ventilation}

The information that can be learned about mechanical ventilation from any specific population-level database depends a lot on two main factors. The first is the ability to identify mechanical ventilation accurately in the

\section{实


data (Table 1). The second is the specifics of the clinical details collected that may allow for a more nuanced assessment of mechanical ventilation. In a hierarchy of potential information, at the bottom is the ability to identify whether mechanical ventilation was used at all during hospitalization; at the top is the ability to identify details of ventilator settings and measurements, such as compliance and driving pressures (Fig. 1). With some

Table 1 Validity of codes for determining receipt of mechanical ventilation in selected population-level data

\begin{tabular}{|c|c|c|c|c|c|c|c|c|}
\hline & Data source & $\begin{array}{l}\text { Definition } \\
\text { of mechanical } \\
\text { ventilation }\end{array}$ & $\begin{array}{l}\text { Comparison } \\
\text { standard }\end{array}$ & Sensitivity & Specificity & $\begin{array}{l}\text { Positive } \\
\text { predictive } \\
\text { value }\end{array}$ & $\begin{array}{l}\text { Negative } \\
\text { predictive } \\
\text { value }\end{array}$ & Accuracy \\
\hline Quan et al. [14] & $\begin{array}{l}\text { Hospital discharge } \\
\text { data from three } \\
\text { hospitals in } \\
\text { Calgary }\end{array}$ & ICD-9 codes $(96.7 x)$ & Chart review & 87.0 & 99.7 & 93.0 & 99.5 & 0.9 \\
\hline Garland et al. [15] & $\begin{array}{l}\text { Canadian Dis- } \\
\text { charge Abstract } \\
\text { Database }\end{array}$ & $\begin{array}{l}\text { CCl codes (GZ.31. } \\
\text { CA-ND, 1.GZ.31. } \\
\text { CR-ND) }\end{array}$ & $\begin{array}{l}\text { Prospectively } \\
\text { collected } \\
\text { clinical database } \\
\text { (Winnipeg ICU } \\
\text { database) }\end{array}$ & 91.5 & 94.4 & 94.8 & 90.9 & 0.93 \\
\hline $\begin{array}{l}\text { Blichert-Hansen } \\
\text { et al. [16] }\end{array}$ & $\begin{array}{l}\text { Danish National } \\
\text { Patient Registry }\end{array}$ & $\begin{array}{l}\text { Danish procedure } \\
\text { codes }\end{array}$ & Chart review & - & - & 100 & - & - \\
\hline Wunsch et al. [17] & Medicare data & ICD-9 codes (96.7x) & $\begin{array}{l}\text { Prospectively } \\
\text { collected } \\
\text { clinical database } \\
\text { (APACHE Out- } \\
\text { comes) }\end{array}$ & 58.4 & 96.0 & 89.6 & 79.7 & - \\
\hline Kerlin et al. [18] & $\begin{array}{l}\text { Electronic health } \\
\text { records from } \\
\text { two US health } \\
\text { systems }\end{array}$ & ICD-9 codes (96.7x) & $\begin{array}{l}\text { Chart review, vali- } \\
\text { dated electronic } \\
\text { algorithm }\end{array}$ & $38.0,46.0$ & $99.6,99.6$ & - & - & $0.73,0.69$ \\
\hline
\end{tabular}

ICD-9 International Classification of Disease, 9th edition, CCI Canadian Classification of Health Interventions

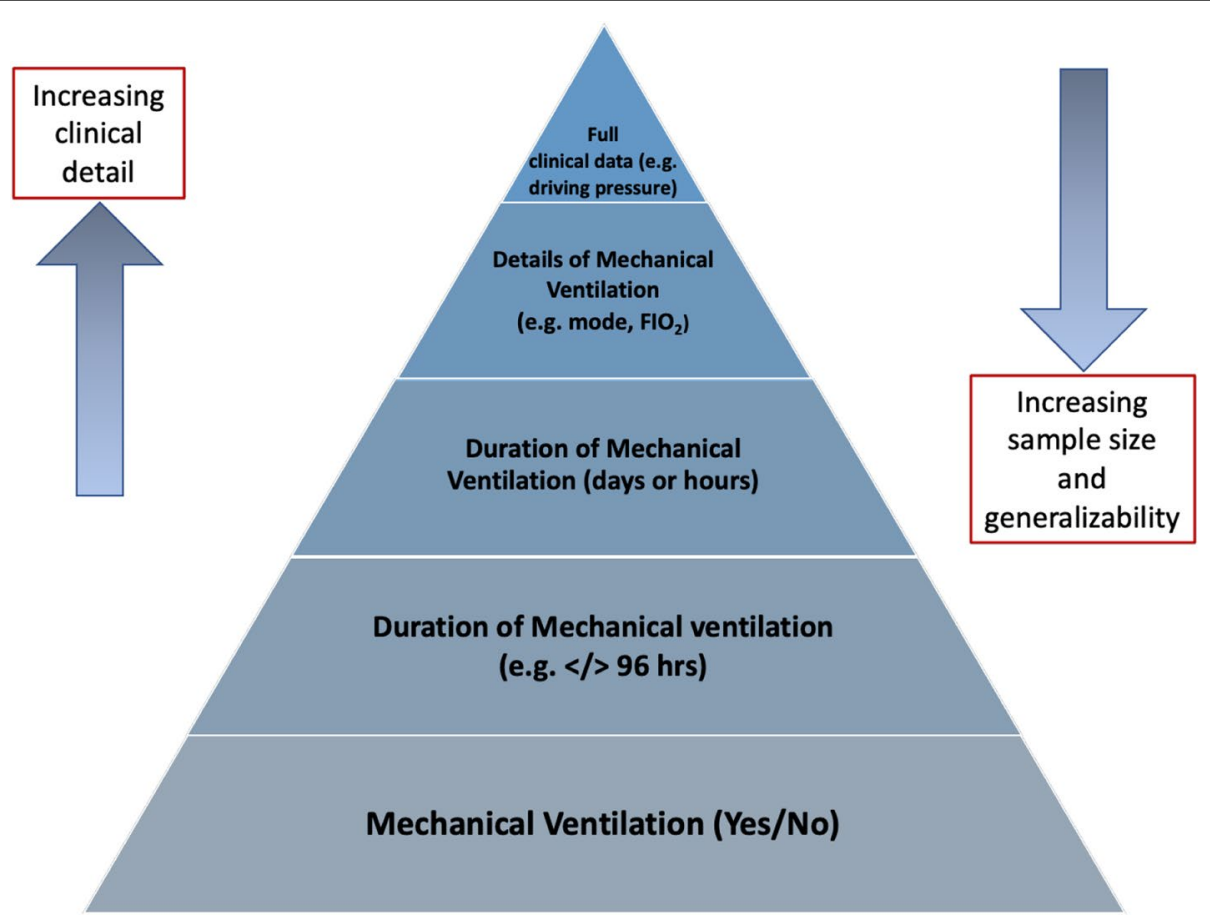

Fig. 1 Schematic of information in databases including information on mechanical ventilation 
exceptions, large databases tend to include information that falls towards the bottom of this hierarchy. In particular, these databases often lack the clinical variables required to ascertain patient severity of illness, hindering the ability to adjust for differences in casemix. As the available detail increases, the cohort sample size often decreases, resulting in a loss of population coverage for databases with these most detailed components.

Some countries, such as the United Kingdom and Australia, have the ability to track essentially all use of mechanical ventilation at hospitals, linked with detailed clinical data that allow for a rich assessment of casemix and outcomes (although even these databases do not contain the detailed physiology and mechanical ventilation settings described above). In the United States, population-level data are often collected for administrative purposes. Consequently, mechanical ventilation is often identifiable solely through International Classification of Diseases (ICD)-9 and -10 codes which, at their best, only indicate its use at some point during hospitalization and the broad duration of time (less than or more than $96 \mathrm{~h}$ ). Moreover, when the validity of these procedure codes have been examined, they had high specificity (>95\%) but low sensitivity (42-58\%), with substantial variability in sensitivity across different US hospitals [17, 18]. The patients in a cohort defined by these ICD codes are, therefore, very likely to have received mechanical ventilation. However, due to the low sensitivity, many patients who also received mechanical ventilation are likely to have been excluded. Knowledge of these performance characteristics is necessary to appropriately interpret population-level data, as understanding (and potentially quantifying) how misclassification may impact results will ensure robust conclusions from the data. Even taking these considerations into account, population-averaged data are of limited utility to guide clinical decisions for individual patients. While these data may inform discussion of potential outcomes, the likelihood of a particular outcome occurring for a given patient is often poorly predicted, even when using high-quality clinical data [19].

Despite its shortcomings, population-level data have greatly furthered our understanding of how mechanical ventilation is used and associated outcomes for patients. With growing facility with artificial intelligence techniques that can process and enrich extremely large amounts of data, there is the potential to gain more nuanced insights from large population-level datasets that also include more detailed clinical information [20]. It is incumbent on us to continue to assess such realworld evidence to improve our understanding of how to best provide life-sustaining therapies, such as mechanical ventilation.

\begin{abstract}
Author details
${ }^{1}$ Department of Anesthesiology, Columbia University, New York, NY, USA.

${ }^{2}$ Department of Epidemiology, Mailman School of Public Health, Columbia University, New York, NY, USA. ${ }^{3}$ Division of Pulmonary, Critical Care, and Sleep Medicine, University of Miami Miller School of Medicine, Miami, FL, USA.

${ }^{4}$ Albert Einstein College of Medicine, Division of Critical Care, Bronx, NY, USA.

${ }^{5}$ Department of Critical Care Medicine, Sunnybrook Health Sciences Centre, 2075 Bayview Ave, Rm D1.08, Toronto, ON M4N 3M5, Canada. ${ }^{6}$ Department of Anesthesia and Interdepartmental Division of Critical Care Medicine, University of Toronto, Toronto, ON, Canada.
\end{abstract}

\section{Funding}

Dr. Hannah Wunsch is supported by a Tier 2 Canada Research Chair in Critical Care Organization and Outcomes and by a Research Merit Award from the Department of Anesthesia at the University of Toronto. Dr. May Hua is supported by a Paul B. Beeson Career Development Award K08AG051184 from the National Institute on Aging and the American Federation for Aging Research.

\section{Compliance with ethical standards}

\section{Conflict of interest}

On behalf of all authors, the corresponding author states that there is no conflict of interest.

\section{Publisher's Note}

Springer Nature remains neutral with regard to jurisdictional claims in published maps and institutional affiliations.

Received: 1 July 2020 Accepted: 8 August 2020

Published online: 26 August 2020

\section{References}

1. Zilberberg MD, de Wit M, Pirone JR, Shorr AF (2008) Growth in adult prolonged acute mechanical ventilation: implications for healthcare delivery. Crit Care Med 36:1451-1455

2. Borjaille CZ, Hill AD, Pinto R, Fowler RA, Scales DC, Wunsch H (2019) Rates of mechanical ventilation for patients with dementia in ontario: a population-based cohort study. Anesth Analg 129:e122-e125

3. Zilberberg MD, de Wit M, Shorr AF (2012) Accuracy of previous estimates for adult prolonged acute mechanical ventilation volume in 2020: update using 2000-2008 data. Crit Care Med 40:18-20

4. Wunsch $H$, Linde-Zwirble WT, Angus DC, Hartman ME, Milbrandt EB, Kahn JM (2010) The epidemiology of mechanical ventilation use in the United States. Crit Care Med 38:1947-1953

5. Kahn JM, Goss CH, Heagerty PJ, Kramer AA, O'Brien CR, Rubenfeld GD (2006) Hospital volume and the outcomes of mechanical ventilation. N Engl J Med 355:41-50

6. Kahn JM, Ten Have TR, Iwashyna TJ (2009) The relationship between hospital volume and mortality in mechanical ventilation: an instrumental variable analysis. Health Serv Res 44:862-879

7. Carson SS, Cox CE, Holmes GM, Howard A, Carey TS (2006) The changing epidemiology of mechanical ventilation: a population-based study. J Intensive Care Med 21:173-182

8. Mehta AB, Syeda SN, Bajpayee L, Cooke CR, Walkey AJ, Wiener RS (2015) Trends in tracheostomy for mechanically ventilated patients in the United States, 1993-2012. Am J Respir Crit Care Med 192:446-454

9. Wunsch H, Guerra C, Barnato AE, Angus DC, Li G, Linde-Zwirble WT (2010) Three-year outcomes for medicare beneficiaries who survive intensive care. JAMA 303:849-856

10. Wunsch $H$, Christiansen CF, Johansen MB, Olsen M, Ali N, Angus DC, Sorensen HT (2014) Psychiatric diagnoses and psychoactive medication use among nonsurgical critically ill patients receiving mechanical ventilation. JAMA 311:1133-1142

11. Hill AD, Fowler RA, Burns KEA, Rose L, Pinto RL, Scales DC (2017) Longterm outcomes and health care utilization after prolonged mechanical ventilation. Ann Am Thorac Soci 14:355-362 
12. Shih C-Y, Hung M-C, Lu H-M, Chen L, Huang S-J, Wang J-D (2013) Incidence, life expectancy and prognostic factors in cancer patients under prolonged mechanical ventilation: a nationwide analysis of 5,138 cases during 1998-2007. Crit Care 17:R144

13. Teno JM, Gozalo P, Khandelwal N, Curtis JR, Meltzer D, Engelberg R, Mor $V(2016)$ Association of increasing use of mechanical ventilation among nursing home residents with advanced dementia and intensive care unit beds. JAMA Intern Med 176:1809-1816

14. Quan H, Parsons GA, Ghali WA (2004) Validity of procedure codes in International Classification of Diseases, 9th revision, clinical modification administrative data. Med Care 42:801-809

15. Garland A, Marrie RA, Wunsch H, Yogendran M, Chateau D (2020) Accuracy of administrative hospital data to identify use of life support modalities. A Canadian study. Ann Am Thorac Soc 17:229-235

16. Blichert-Hansen L, Nielsson MS, Nielsen RB, Christiansen CF, Nørgaard M (2013) Validity of the coding for intensive care admission, mechanical ventilation, and acute dialysis in the Danish National Patient Registry: a short report. Clin Epidemiol 5:9-12

17. Wunsch H, Kramer A, Gershengorn HB (2017) Validation of intensive care and mechanical ventilation codes in medicare data*. Crit Care Med 45:e711-e714

18. Kerlin MP, Weissman GE, Wonneberger KA, Kent S, Madden V, Liu VX, Halpern SD (2016) Validation of administrative definitions of invasive mechanical ventilation across 30 intensive care units. Am J Respir Crit Care Med 194:1548-1552

19. Rojas JC, Carey KA, Edelson DP, Venable LR, Howell MD, Churpek MM (2018) Predicting intensive care unit readmission with machine learning using electronic health record data. Ann Am Thorac Soc 15:846-853

20. Cosgriff CV, Celi LA, Stone DJ (2019) Critical care, critical data. Biomed Eng Comput Biol 10:1179597219856564 